\title{
Packing size effect on the liquid circulation property in an external-loop packed bubble column
}

\author{
Yanling Tang ${ }^{1}$, Gang Luo ${ }^{2}$, and Zhenmin Cheng ${ }^{1}$ \\ ${ }^{1}$ East China University of Science and Technology \\ ${ }^{2} \mathrm{ECUST}$
}

December 5, 2021

\begin{abstract}
Packing size effects on the fluid dynamics in an external-loop packed bubble column with Raschig rings of three different effective diameters $(5,14$ and $41 \mathrm{~mm})$ in the riser were investigated. The overall gas holdup, liquid circulating velocity and gasliquid mass transfer coefficient were respectively measured by volume expansion method, tracer-response method and dynamic oxygen-absorption technique. CFD simulation with the Euler-Euler two-fluid method was used to predict the liquid circulating velocity by treating the packing as a porous medium. Compared to the empty column, the gas holdup was found to increase with the presence of packing, however, the liquid circulating velocity and gas-liquid mass transfer coefficient may increase or decrease. Specifically, the gas holdup increases with the decrease of packing size, while the liquid circulating velocity is on the contrary, which induces the maximal gas-liquid mass transfer rate at packing diameter of $14 \mathrm{~mm}$.
\end{abstract}

\section{Hosted file}

manuscript.pdf available at https://authorea.com/users/449552/articles/548059-packing-sizeeffect-on-the-liquid-circulation-property-in-an-external-loop-packed-bubble-column 